\title{
INTERESSE DAS CRIANÇAS, PEDAGOGIA DE PROJETOS E METACOGNIÇÃO: artes de governar a docência na educação infantil
}

\author{
CHILDREN'S INTEREST, PEDAGOGY OF PROJECTS AND METACOGNITION: \\ arts of governing teaching in childhood education \\ INTERÉS DE LOS NIÑOS, PEDAGOGÍA DE PROYECTOS Y METACOGNICIÓN: \\ artes de gobernar la docencia en la educación inicial
}

\author{
Rodrigo Saballa de Carvalho \\ Professor Doutor da Faculdade de Educação da Universidade Federal do Rio Grande do Sul (UFRGS). \\ saballa@terra.com.br
}

Bianca Salazar Guizzo Professora Doutora da Universidade Luterana do Brasil (ULBRA). bguizzo_1@hotmail.com

\begin{abstract}
RESUMO: A partir das contribuições dos estudos desenvolvidos por Michel Foucault, o artigo tem como foco de análise os discursos sobre docência na Educação Infantil presentes em relatórios de estágio de acadêmicas concluintes de um Curso de Licenciatura em Pedagogia. Os discursos presentes nos relatórios são considerados produções históricas constituídas por meio das contribuições de uma matriz pedagógica composta por diferentes proposições teóricas voltadas para a formação de professores. Desse modo, são discutidos os processos de constituição docente, por meio da problematização das estratégias de governamento que produzem as acadêmicas como profissionais de determinado tipo. A partir da análise, é possível inferir que os discursos sobre docência presentes nos relatórios, alicerçados nas noções de respeito aos interesses das crianças, de trabalho com a pedagogia de projetos e do desenvolvimento da prática do "aprender a aprender", constituem regimes de verdade nos quais se evidenciam ressonâncias de postulados escolanovistas ressignificados na forma de pedagogias contemporâneas de Educação Infantil.
\end{abstract}

PALAVRAS-CHAVE: Educação Infantil. Discurso. Docência. Governamento.

ABSTRACT: Based on the contributions of studies developed by Michel Foucault, this article analyzes the discourses on teaching in Childhood Education found in trainee reports written by last-year Education students of.. These discourses are regarded as historical productions by way of contributions of an educational matrix composed of different theoretical propositions aimed at teacher training. Thus, the processes of faculty composition are discussed through problematizing government strategies produced by university students as professionals of a certain type. From this analysis, it can be deduced that discourses about teaching found in the reports, grounded on notions of respect of children's interests, work with pedagogy of projects and development of the practice of "learning to learn" constitute regimens of truth that evidence resonances from redefined New School postulates in the form of contemporary pedagogies in Childhood Education.

KEYWORDS: Childhood Education. Discourse. Teaching. Government.

RESUMEN: Partiendo de los aportes de Michel Foucault en sus estudios, el presente artículo se centra en el análisis de los discursos sobre docencia en la Educación Infantil, presentes en informes de pasantía de académicas en etapa de conclusión de un Curso de Licenciatura en Pedagogía. Los discursos presentes en dichos informes son vistos como producciones históricas constituidas por medio de los aportes de una matriz pedagógica compuesta de diferentes proposiciones teóricas dirigidas a la formación de maestros. De esa forma, se discuten los procesos de constitución docente por medio de la problematización de las estrategias de gubernamentalidad que producen dichas estudiantes como profesionales de determinado tipo. A partir del análisis, se pudo inferir que los discursos sobre docencia presentes en los informes, basados en las nociones de respeto a los intereses de los niños, de trabajo con la pedagogía de proyectos y del desarrollo de la práctica del "aprender a aprender" constituyen regímenes de verdad en los cuales se ponen de manifiesto resonancias de postulados de la Escuela Nueva resignificados en forma de pedagogías contemporáneas de Educación Inicial.

PALABRAS CLAVE: Educación Infantil. Discurso. Docencia. Gubernamentalidad.

$\overline{\text { Artigo recebido em setembro de }} 2016$

Aprovado em novembro de 2016 
INTERESSE DAS CRIANÇAS | Rodrigo Saballa de Carvalho e Bianca Salazar Guizzo

\section{1| INTRODUÇÃO}

O artigo é decorrente de uma pesquisa que, a partir das contribuições dos estudos desenvolvidos por Foucault (1995, 2005, 2007, 2008a, 2008b), tem como foco de análise a descrição do modo como uma certa matriz pedagógica (FABRIS; SILVA, 2015), veiculada em relatórios de estágio de acadêmicas concluintes de um Curso de Licenciatura em Pedagogia, opera no governamento da docência, objetivando e produzindo modos de ser professor de Educação Infantil. A matriz pedagógica em questão, fundamenta-se no ensino ativo, enquanto modo de desenvolver os raciocínios escolares por intermédio da proposição de atividades que lidam com a aprendizagem de conhecimentos classificados como "úteis" e "práticos" (POPKEWITZ, 1994). Nessa direção, a matriz opera a partir de uma metodologia que incentiva o "aprender fazendo" (POÇAS, 2010) das crianças, no qual o prazer e a participação não estão associados apenas ao que é aprendido, mas também ao "fazer para aprender" (ARCE, 2004).

Para tanto, metodologicamente são analisados 40 relatórios de estágio ${ }^{1}$ de Educação Infantil. Por meio da análise do discurso de inspiração foucaultiana, são evidenciadas três táticas, que em nome do ensino ativo (COUTINHO; SOMMER, 2011), colocam em funcionamento a metodologia decorrente da matriz pedagógica em análise. Em relação à primeira tática, são recorrentes nos relatórios, enunciados referentes à importância de serem considerados os interesses das crianças para o planejamento das propostas. No que se refere à segunda, despertam atenção os enunciados que dizem respeito à proposição de projetos como meio para a formação de crianças autônomas, críticas, participativas e flexíveis. Em relação à terceira tática, nota-se a tônica na promoção do desenvolvimento da metacognição ${ }^{2}$ infantil enquanto prática para o desenvolvimento de um cidadão aprendente (POPKEWITZ,1998).

A partir das táticas descritas são selecionados e articulados certos tipos de saberes e impostos procedimentos que incidem na normatização da prática pedagógica (VEIGA-NETO, 2000). Trata-se, portanto, da problematização de uma grade de inteligibilidade que mobiliza e regula as práticas de acadêmicas em formação. Isso porque os escritos presentes nos relatórios de estágio configuram formas de narrar a docência que delineiam, como parte inseparável, uma docência a ser vivida (PALAMIDESSI, 1996). Ao empreenderem a narração de suas práticas, as acadêmicas estabelecem valores, legitimam regras e produzem significados para a docência, pois enunciam como deve ser desenvolvida a ação pedagógica em sala de aula.

Desse modo, os discursos das acadêmicas presentes nos relatórios são considerados como pertencentes a uma matriz pedagógica que os controla, os regula e os posiciona dentro de uma determinada ordem. Isso quer dizer que tais discursos se encontram inseridos em uma racionalidade que corporifica formas particulares das acadêmicas agirem, sentirem, falarem e verem o mundo e o próprio eu (POPKEWITZ, 1994). Por essa razão, interessa mostrar como se organizam e se tramam discursividades históricas que delineiam formas de conceber a ação pedagógica com crianças na Educação Infantil, por meio de uma matriz pedagógica (FABRIS; SILVA, 2015), constituidora de regimes de verdade ${ }^{3}$, cujos fundamentos podem ser considerados como

\footnotetext{
${ }^{1} \mathrm{O}$ corpus de análise da pesquisa foi composto por 40 relatórios de estágio de Educação Infantil de acadêmicas concluintes de um curso de licenciatura em Pedagogia. As participantes da pesquisa, com idades entre 24-35 anos, acadêmicas de uma Universidade localizada na região sul do país, autorizaram a análise de seus relatórios de estágio, mediante a assinatura de um Termo de Consentimento Livre e Esclarecido.

${ }^{2}$ A metacognição pode ser entendida como a capacidade do indivíduo refletir sobre o seus próprios processos de aprendizagem.

${ }^{3}$ A expressão se refere a uma concepção de verdade entendida como maneira de regular e controlar e que não diz respeito apenas àqueles discursos a que atribuímos o suposto status de "dominantes" ou "dominadores" (GORE, 1994). Conforme a autora, todos os discursos podem ser vistos funcionando como regimes de verdade.
} 
INTERESSE DAS CRIANÇAS | Rodrigo Saballa de Carvalho e Bianca Salazar Guizzo

ressonâncias ${ }^{4}$ da discursividade produzida pelo movimento da Escola Nova (DUARTE, 2004; PRADO; AZEVEDO 2012). Movimento que emergiu na virada do século XIX para o XX, especialmente nos Estados Unidos e na Europa, contribuindo para estabelecer uma matriz pedagógica sustentada em um ideário educacional reconhecido como crítico, radical, emancipatório e transformador (LUZURIAGA, 1967, MATTOS, 2008, COUTINHO; SOMMER, 2011). Ideário inspirado em grande parte pelo trabalho de John Dewey e William Kilpatrick, tendo em Anísio Teixeira, a partir da década de 1930, o seu principal expoente em terras brasileiras.

Dentro dessa lógica, a concepção educacional dos escolanovistas pautou-se na ideia de que a escola era uma (micro) sociedade e, por isso, necessitava de uma pedagogia progressista capaz de produzir indivíduos orientados à democracia, à igualdade e à cooperação (LEITE, 2007; BIN, 2012). Desta forma, o movimento escolanovista teve como meta central a ruptura com a pedagogia tradicional. Defendeu o deslocamento da disciplina para uma educação focalizada nos modos de pensamento, aprendizagem, interesse e liberdade voltados para a expressão das manifestações individuais e espontâneas das crianças. Em tal perspectiva, os trabalhos teóricos de Dewey (2002), dentre as contribuições de outros escolanovistas, apresentou uma contraposição aos pressupostos do ensino expositivo, que tomava a transmissão do conteúdo pelo professor como estratégia principal de funcionamento da aula. Partindo do argumento de que a educação era vida, e não preparação, o referido autor problematizou as concepções de aprendizagem vigentes e os modos de organização da escola.

Nesse sentido, Dewey (2002, 2011), realizou uma análise comparativa entre os mundos escolar e infantil, evidenciando um descompasso entre ambos. Diante disso, argumentou sobre a necessidade de conciliação entre a criança e a experiência, tornando a prática pedagógica um saber técnico (LUZIRIAGA, 1967). Ou seja, a concepção científica de educação de Dewey (2002) colaborou para que os saberes escolares passassem a ser investidos de um poder sem precedentes, governando docentes e crianças, não apenas por sua autoridade moral, mas também pelo estatuto de saber pedagógico que foi assumido pelos docentes como modo de oposição ao ensino considerado tradicional, centrado nos conteúdos e na transmissão de conhecimentos.

A partir das considerações expostas, é possível dizer que os discursos da pedagogia constroem um campo a partir do qual o ensino é visto, pensado, sentido e posto em funcionamento (POPKEWITZ, 1994). Por essa razão, o ideário escolanovista foi ressignificado no decorrer dos anos, passando a funcionar contemporaneamente de modo naturalizado como base de configuração de uma matriz pedagógica que tem os interesses das crianças como princípio, o trabalho com projetos como meio e a metacognição como fim da ação pedagógica. Desse modo, justifica-se a importância das análises que serão apresentadas no presente artigo, tendo em vista a problematização da naturalidade com que são enunciados e difundidos os discursos sobre a docência na Educação Infantil, evidenciando os modos pelos quais as acadêmicas se governam (e são governadas), nomeiam (e definem) o exercício profissional em seus escritos (WALKERDINE, 1998).

Prosseguindo a discussão, para melhor compreensão do leitor, na próxima seção, serão apresentados os posicionamentos teórico-metodológicos, bem como os conceitos foucaultianos de governamento e discurso que serão utilizados como ferramentas analíticas. Nas três seções subsequentes serão apresentadas as análises dos discursos sobre docência presentes nos relatórios de estágio. Por fim, na última seção, serão apresentadas as considerações finais.

\footnotetext{
${ }^{4}$ Certamente, os discursos que serão analisados nos relatórios de estágio não são os mesmos que foram enunciados pelos teóricos escolanovistas. Tratam-se apenas de ressonâncias que repercutem atualmente em pedagogias consideradas inovadoras e progressistas. Isso porque mudaram as condições nas quais foram enunciados os discursos, configurando resignificações nos modos de conceber a docência.
} 


\section{2 | DISCURSO E GOVERNAMENTO COMO FERRAMENTAS ANALÍTICAS}

Partindo dos aspectos apresentados na introdução, convém reiterar que os discursos que serão analisados nos relatórios de estágio, encontram-se implicados no governamento ${ }^{5}$ (FOUCAULT, 2008a, 2008b) da docência na Educação Infantil, a partir de uma matriz pedagógica (FABRIS; SILVA, 2015) que tem como tônica a explicitação de um certo modo de ser professor de crianças pequenas. Isso quer dizer que os discursos decorrentes da matriz pedagógica em questão, posicionam as acadêmicas em certos modos de ser e de existir no mundo, atribuindo valores, estilos de vida e determinadas representações da profissão docente (DUBET, 2006).

Desse modo, cabe discorrer sobre os conceitos foucaultianos de discurso e governamento, pelo fato dos mesmos serem centrais nas análises que serão apresentadas nas seções subsequentes. Em primeiro lugar, é preciso esclarecer que não existem discursos ocultos. São os discursos que definem regimes de verdade (FOUCAULT, 2005; 2007), tornando possível tanto aquilo que pode ser dito, como aquilo que pode ser feito, tanto o objeto da ciência como o objeto da prática pedagógica. Por essa razão, é imprescindível discutir como são estabelecidos os critérios que definem o que é concebido como verdadeiro, tomando como foco da análise do discurso os regimes de verdade (GORE, 1994). Por exemplo, no caso das análises que serão apresentadas, será evidenciado o modo como discursos sobre docência com crianças pequenas, supostamente contemporâneos e progressistas, estão articulados a uma matriz pedagógica, cujos antecedentes datam da discursividade produzida pelo Movimento da Escola Nova (LUZURIAGA, 1967).

A partir de tais colocações, é possível dizer que os discursos sobre a docência na Educação Infantil estão marcados por uma ordem mais ampla (PALAMIDESSI, 1996). Em vista disso, é preciso destacar que as acadêmicas participantes da pesquisa não são consideradas criadoras dos discursos presentes em seus relatórios. Tampouco, a problematização desses discursos, consiste em uma análise das relações entre as acadêmicas e o que elas escreveram sobre suas práticas, mas no destaque da posição que as mesmas, enquanto indivíduos, ocupam tendo em vista tornarem-se o modelo de professora de Educação Infantil pretendida pela matriz pedagógica. Ratificando esse argumento, Foucault $(1995,2007)$ afirma que o sujeito do enunciado não é a origem do discurso, mas um lugar vazio que vários podem ocupar. Isso significa que, na especificidade da análise do discurso, é preciso atentar para as posições de sujeito que o enunciado delimita (FOUCAULT, 2005).

Em tal linha argumentativa, é preciso destacar que os discursos cumprem determinadas funções dentro de sistemas estratégicos em que o poder se encontra implicado e pelo qual funciona, tendo sentido somente a partir de sua exterioridade. Desse modo, fica claro que as acadêmicas participantes da pesquisa não constroem sentidos e significados sobre a docência de maneira livre, mas através de uma série de sistemas de restrições e incitações discursivas que constituem uma determinada ordem (GORE,1994). Reiterando esse argumento, Foucault (2005) afirma que ninguém entra na ordem do discurso se não satisfizer a certas exigências ou se não for, de início, qualificado para fazê-lo. Por essa razão, é possível afirmar que os discursos sobre a docência na Educação Infantil constroem a realidade pelo campo de possibilidades que ativam.

No caso das análises que serão apresentadas, o governamento (FOUCAULT, 2008a, 2008b) das acadêmicas operacionaliza-se a partir de uma determinada matriz pedagógica que por meio de suas táticas - sondagem dos interesses das crianças, trabalho a partir da pedagogia de projetos

\footnotetext{
${ }^{5}$ Nos casos em que estiver sendo tratada a questão da ação ou ato de governar, será utilizado o termo governamento ao invés de governo.
} 
e metacognição - definem um modo particular de atuação em sala de aula e um perfil profissional a ser seguido. Corroborando o argumento, Dean (1999) define o conceito de governamento como qualquer direcionamento calculado da conduta humana. Nesse caso, conduta se refere a comportamentos, ações e também noções morais de autogestão e de autorregulação (FOUCAULT, 2008b). Por essa razão, é possível afirmar que o governamento ocorre a partir de normas particulares que se operacionalizam através de práticas desenvolvidas por uma multiplicidade de autoridades e de agências que procuram, através do emprego de uma variedade de técnicas e saberes, incitar escolhas e desejos. Por exemplo, o governamento das acadêmicas, enquanto futuras docentes, têm início desde a entrada na graduação, quando as mesmas passam por um processo intenso de apropriação "de um conjunto de saberes e de práticas, que medeiam a relação que cada uma irá estabelecer consigo mesma de modo a direcionar a sua própria conduta como docente" (COUTINHO; SOMMER, 2011, p. 98).

Em tal perspectiva, o governamento caracteriza-se pela unificação de estratégias produtivas que têm o intuito de atingir fins políticos, conduzindo a todos e a cada um, através de um processo que, ao mesmo tempo, individualiza, totaliza e normaliza (DEAN, 1999; FOUCAULT, 2008a). Isso porque, a questão em pauta não é nunca da ordem da coerção e dos constrangimentos exercidos sobre a massa dos governados, mas da produção de indivíduos intervenientes nos jogos e nas relações de poder, os quais supostamente vivenciam mais autonomia e liberdade.

Em suma, o governamento depende de sujeitos livres, sendo constituído por um conjunto de práticas estratégicas que indicam formas por meio das quais as acadêmicas conduzem a si e aos outros. Práticas que produzem individualidades docentes autogovernadas (POPKEWITZ, 1998) e que são operacionalizadas por meio da disseminação e naturalização de discursos historicamente constituídos sobre a docência na Educação Infantil. A partir dessa exposição, pode-se que os discursos sobre a docência presentes nos relatórios de estágio têm efeitos sobre a conduta das acadêmicas, já que os mesmos incidem nas práticas pedagógicas delas, disciplinando corpos, fixando tempos, espaços e inventando subjetividades. Nesse sentido, prosseguindo a discussão, na próxima seção será apresentada a primeira unidade de análise, a qual enfoca o interesse infantil como princípio da prática docente.

\section{O interesse infantil como princípio da prática docente}

O estágio com a turma do Jardim B foi sensacional. Observei os interesses das crianças [...] e fiz uma seleção de temas possíveis para o projeto de estágio: pássaros silvestres e circo. Ambos haviam sido foco de discussão nas aulas. Fiz uma roda com as crianças, apresentei os temas e por votação elas definiram que o tema do projeto seria circo. Durante a realização do projeto, observando a motivação de toda a turma, percebi que os interesses das crianças são o estopim de um trabalho de sucesso. (Transcrição de Relatório de Estágio - A25 ${ }^{6}$ )

Desde que iniciei as observações já sabia que teria que descobrir quais eram os interesses dos bebês. A partir das observações, percebi que os bebês gostavam muito de engatinhar pela sala, mas o espaço destinado para essa proposta era restrito devido ao número excessivo de berços e carrinhos. Apostei na mudança do espaço. Reposicionei os berços e criei dois percursos sensoriais. Um percurso interno, composto por um grande tapete das sensações (com diferentes texturas e materiais de manipulação), e um percurso externo para engatinharem no gramado. Foi emocionante perceber a motivação dos bebês, pois pela primeira vez na escola, seus interesses de aprendizagem estavam sendo realmente respeitados. (Transcrição de Relatório de Estágio - A29)

\footnotetext{
${ }^{6}$ A identificação das acadêmicas participantes da pesquisa será apresentada a partir da convenção A (acadêmica) e $n^{\circ}$ (número), tendo em vista a manutenção do anonimato da identidade das participantes.
} 
Aprendi com as leituras que realizei que temos que partir do interesse das crianças para o planejamento, pois assim poderão construir conhecimentos significativos. A partir de um álbum de figurinhas de dinossauros que um aluno trouxe para roda durante o meu período de observações, percebi o interesse das crianças em relação a esse tema. Quando anunciei para turma que o projeto seria sobre dinossauros, foi uma festa! Todos ficaram contentes, pois estavam interessados em pesquisar sobre os primeiros habitantes da terra. Sem dúvida o interesse das crianças possibilita que o trabalho aconteça de verdade. (Transcrição de Relatório de Estágio - A08)

Aprendi com as leituras que realizei durante o Curso de Pedagogia, que temos que sempre partir dos interesses das crianças para o planejamento de nossas propostas em sala de aula. Somente desse modo, as crianças terão a oportunidade de construir conhecimentos significativos. Em meu estágio com uma turma de maternal, percebi que os interesses das crianças são os propulsores de todo o trabalho pedagógico. (Transcrição de Relatório deEstágio-A15)

A partir da leitura dos excertos, é possível observar a centralidade que assume a noção de interesse nos relatórios. Descobrir os interesses de aprendizagem das crianças por meio de observações, conversas e avaliações das aulas, respeitar os interesses das crianças como modo de potencializar seu protagonismo e selecionar temas para o planejamento a partir da observação dos interesses do grupo são enunciados recorrentes nos relatórios. Tais enunciados, conforme Popkewitz (1994), estabelecem regras e padrões que guiam a docência, inscrevendo atributos de subjetividade nos modos como as acadêmicas se constituem enquanto profissionais que atuam com crianças pequenas.

Desse modo, as acadêmicas ao descreverem a organização de suas aulas, as atividades e as estratégias desenvolvidas por elas no intuito de promover aprendizagens, evidenciam que, para planejar suas propostas de trabalho, tomam a noção de interesse como princípio da prática docente. Nessa perspectiva, consideram as crianças como base das ações educativas, em torno das quais as propostas devem ser planejadas e operacionalizadas, tendo em vista o exercício do que consideram uma docência progressista. Conforme Dubet (2006), esse ideário pedagógico contrapõe-se às pedagogias nomeadas tradicionais, cujas práticas centram-se no professor enquanto "detentor" do saber e "condutor" do processo de ensino-aprendizagem.

Em razão disso, conforme Sommer e Coutinho (2008), passam a ser desenvolvidas nas escolas práticas pedagógicas, nas quais se percebe o deslocamento do eixo do ensino para o eixo da aprendizagem. A esse respeito, Stemmer (2006) afirma que também é possível observar uma espécie de economia de ensino, que funciona a partir da promoção da liberdade e da atividade espontânea das crianças enquanto reguladores da aprendizagem. Nesse contexto, o interesse passa a ser significado como algo natural, próprio do sujeito infantil, e a aprendizagem como consequência da livre e espontânea atividade da criança.

Desse modo, convém esclarecer que o princípio de se basear nos interesses das crianças para o planejamento das propostas pedagógicas não é algo recente no contexto educacional. Embora a noção de interesse venha sendo historicamente ressignificada no discurso pedagógico, ela é emergente dos estudos desenvolvidos por Herbart (2003) já no início do século XIX, sendo posteriormente desenvolvida pelos teóricos da Escola Nova, dentre os quais se destacam Claparède (1940), Decroly (2007), Dewey (2002, 2011), Teixeira (1967), entre outros.

Através dos estudos de Herbart (2003) que a noção de interesse assumiu centralidade no processo educativo. Ele concebeu o interesse como o motor da instrução educativa, argumentando que o professor deveria observar as tendências das crianças para orientar seu governo. A proposição defendida por ele era de que o interesse estava presente na natureza infantil, devendo ser descoberto a partir da observação atenta do professor.

Por sua vez, Claparède (1940, p.1) defendeu a importância de uma educação funcional, através da qual o professor deveria tomar "o interesse da criança em atingir um fim como alavanca para o 
desenvolvimento da atividade" proposta. Conforme defendia o autor, a atividade escolar deveria sempre ser suscitada pelo interesse da criança em saber, em investigar, em olhar e em trabalhar, pois um ato que não estivesse direta ou indiretamente ligado aos seus interesses seria algo contra a natureza infantil.

Diante dessa lógica de pensamento, Decroly (2007) apresentou um método de trabalho intitulado centros de interesse. O método consistia em conhecer os interesses autênticos das crianças e selecionar os assuntos a serem trabalhados a partir de um enfoque globalizado. Conforme Mattos (2008), Decroly acreditava que somente o interesse da criança produziria conhecimento e a possibilidade de afastamento da rigidez e sistematização da escola tradicional. Além disso, considerava a curiosidade infantil como promotora do interesse e este como expressão das necessidades da criança. Por essa razão, o ensino deveria ser planejado em função dos interesses das crianças, já que eles eram considerados decorrentes das necessidades naturais infantis de se alimentar, de se vestir e de trabalhar.

Por sua vez, Dewey $(2002,2011)$, em suas proposições teóricas, também ressaltou que a prática docente deveria ser pautada pelo respeito aos interesses das crianças, porém apresentou um elemento novo às discussões desenvolvidas por seus antecessores, discutindo de modo integrado os conceitos de interesse e esforço. De acordo com Mattos (2008), Dewey, em 1898, publicou a obra intitulada Interesse e Esforço, em que apresentou exemplos referentes ao uso de ambos os conceitos e esclarecimentos para sua compreensão articulada no contexto educacional. Desse modo, o interesse era considerado pelo autor como signo de uma capacidade em crescimento. Em Dewey, a noção de interesse era vista de modo integrado à de esforço. O argumento era que a criança somente empregaria suas energias na compreensão de ideias e fatos quando estivesse interessada pelo objeto de conhecimento. Para Dewey (2011), seria exclusivamente por meio da observação dos interesses da criança que o professor teria a possibilidade de entrar no universo infantil, a fim de descobrir o que ela estaria disposta a aprender. Nesse sentido, os conceitos de interesse e esforço foram concebidos de modo interdependente pelo autor. Desse modo, é possível afirmar que, para Dewey (2002), o interesse foi considerado indissociável do esforço, pois o autor defendia a máxima de que sempre que houvesse interesse para a realização de uma atividade, o esforço estaria presente.

Associado à lógica de pensamento de Dewey, Teixeira (1967), um dos principais responsáveis por divulgar no Brasil as formulações teóricas do referido autor, defendia que os novos métodos de ensino deveriam ser "os despertadores do interesse", assim como as escolas deveriam desenvolver nas crianças os hábitos de observação e raciocínio, despertando-lhes o interesse pelos ideais e conquistas da humanidade. Teixeira (1967) defendia que, se o método pedagógico estivesse apropriado, o interesse seria despertado naturalmente. Enquanto leitor de Dewey, Teixeira (1967) argumentava que o interesse ocorreria como resultado da relação entre a criança e o seu objeto de desejo. Em tal perspectiva, o autor declarava que a função da educação seria a de fazer a criança descobrir e compreender os interesses verdadeiros de sua vida, utilizando a inteligência e a razão no seu julgamento.

A partir da exposição apresentada a respeito dos posicionamentos de alguns autores da Escola Nova sobre a noção de interesse, cabe esclarecer que os estudos dos teóricos citados podem ser considerados como condição de possibilidade para a emergência da defesa do interesse como princípio da prática docente na Educação Infantil. Diante dessa lógica de pensamento, é necessário destacar que a recorrência da noção de interesse nos relatórios de estágio analisados não é algo natural, mas faz parte de um discurso pedagógico atravessado por uma vontade de entender a criança, explicá-la, descrevê-la e capturá-la, no intuito de encontrar elementos que possibilitem descobrir a melhor forma de governá-la (WALKERDINE, 1998). 
Após compromisso assumido pelo Estado brasileiro na III Conferência Mundial de Combate ao Racismo, Discriminação Racial, Discriminação Racial, Xenofobia e Intolerância Correlata em Durban, África do Sul, realizada no 31 de agosto a 8 de setembro de 2001, portanto, já quase no final do segundo governo de Fernando Henrique Cardoso, caberia ao novo presidente do Brasil, criar meios e políticas para a consolidação dessa perspectiva no conjunto de suas políticas de diversidade.

Ao ser eleito em 2002 e assumir o governo em 2003, o governo de Luís Inácio Lula da Silva, tinha como parte de seu plano de governo atender parte das demandas históricas de movimentos sociais e que se embora de forma fragmentada ocorriam, seria necessário uma maior intencionalidade e priorização da agenda e efetividade de ações. Assim, nesse primeiro ano de governo, o então recém-eleito presidente da república cria duas importantes secretarias, cujo papel seria atender e ampliar o atendimento às demandas das mulheres brasileiras e do movimento negro, respectivamente: Secretaria Especial de Políticas para as Mulheres (SPM) e a Secretaria Especial de Políticas de Promoção da Igualdade Racial (SEPPIR). Ainda no ano de 2003, por meio da Lei n. 10.639, de 9 de janeiro a LDBEN 9394/1996 fora alterada, incluindo no currículo oficial da Rede de Ensino a obrigatoriedade da temática "História e Cultura Afro-Brasileira" e na mesma lei, por meio do Art. 79-B no calendário escolar fora incluído o dia 20 de novembro como 'Dia Nacional da Consciência Negra'.

No ano de 2004, na gestão do ministro da Educação Tarso Genro, foi criada a SECAD (Secretaria de Educação Continuada, Alfabetização e Diversidade), como um órgão que passaria a compor a estrutura administrativa do Ministério da Educação, cuja principal finalidade seria a de, junto com outras três secretarias (SEB-Secretaria de Educação Básica, Setec-Secretaria de Educação Tecnológica e Secretaria do Ensino Superior - SESU) articular, criar e ampliar políticas de acesso à educação para todos, a partir das demandas centradas na diversidade e especificidades, a saber: gênero, idade, raça e etnia, etc. Das três secretarias, segundo Moehlecke (2009), foi a SECAD que melhor explicitou as suas ações, compreensões e encaminhamentos sobre a diversidade, visto ampliar posicionamento crítico sobre as oportunizações sociais para e além das políticas das diferenças.

A esse respeito, Dubet (2006) afirma que as propostas pedagógicas denominadas como sendo de interesse das crianças adquiriram um importante significado na educação contemporânea. De acordo com o autor, atualmente é preciso compreender, reconhecer e, sobretudo, tornar as crianças protagonistas. Corroborando o argumento apresentado, Prado e Azevedo (2012) e Stemmer (2006) afirmam que a visão que privilegia o desenvolvimento do trabalho pedagógico a partir dos interesses da criança tem repercutido hegemonicamente no que se refere ao trabalho pedagógico sendo desenvolvido na Educação Infantil. Esses argumentos são potentes para problematizar os discursos presentes nos relatórios de estágio que defendem os interesses das crianças como fundamentos indeléveis à prática educativa.

É preciso compreender, como esclarece Dubet (2006), que não existem "autênticos interesses" a serem descobertos pelo professor para serem incorporados em uma metodologia de ensino considerada progressista, assim como não existe um único modo de exercício da docência. O que existe é um regime de verdade, emergente de uma matriz pedagógica (FABRIS; SILVA, 2015), que vem historicamente governando as subjetividades docentes, por meio de discursos que operam na partilha entre o bom e o mau professor de Educação Infantil.

\section{A pedagogia de projetos como meio de operacionalização da prática docente}


Durante o meu estágio, percebi a importância do trabalho com projetos. A partir de uma reportagem de re-
vista que li para as crianças sobre as baleias, percebi o interesse das mesmas em saber mais sobre
os animais marinhos. Listamos inúmeras perguntas. As questões iniciais foram sobre as baleias. Onde
vivem? O que comem? Quanto tempo vivem? Quais são as espécies? Existem baleias no Brasil? Pas-
sados alguns dias, as crianças também começaram a fazer perguntas sobre os golfinhos e tubarões.
Desse modo, decidimos que o projeto seria sobre os animais marinhos, como modo de contemplar to-
das as demandas do grupo. Aprendi com o desenvolvimento do projeto que é importante valorizar os sa-
beres das experiências, ou seja, as crianças aprendem em ação. Além disso, outro aprendizado impor-
tante foi o de que o trabalho com projetos promove os valores democráticos em sala de aula, superando
as práticas tradicionais centradas no comando da professora. (Transcrição de Relatório de Estágio -A23)

Acredito no trabalho com projetos como a única forma de romper com a educação tradicional das escolas que se baseiam na disciplina e no ensino de conteúdos. Durante o desenvolvimento do projeto [...], tive a possibilidade de observar as crianças exercendo o protagonismo infantil ao buscarem respostas para as suas próprias indagações. O foco do projeto que desenvolvi com a turma foi a musicalização. O projeto partiu de um interesse das crianças sobre os sons produzidos pelo corpo. Como o interesse das crianças persistiu, resolvemos desdobrar o estudo inicial em uma pesquisa sobre instrumentos musicais, pois eles amaram o trabalho com a produção de sons. (Transcrição de Relatório de Estágio - A04)

No desenvolvimento de minha prática docente no estágio de Educação Infantil, tive a oportunidade de mostrar para a professora regente que é possível romper com o ensino tradicional. Tenho certeza que através do meu exemplo consegui mostrar o que é uma prática docente qualificada na Educação Infantil. Trabalhando com um projeto sobre o circo, foi possível colocar as crianças em movimento além de potencializar a participação de todos. As acrobacias e os malabarismos fizeram parte de minhas tardes com as crianças. Além de realizarmos uma bela pesquisa sobre a história do circo e seus profissionais, tivemos a oportunidade de realizar uma visita a um circo que estava na cidade. As crianças tiveram a oportunidade de construir conhecimentos sobre a temática de pesquisa e também de participar ativamente. (Transcrição de Relatório de Estágio - A05)

A pedagogia de projetos, conforme afirma Poças (2010, p. 86), faz parte de um "conjunto de discursos que emulam a produção de sujeitos mais autônomos e flexíveis" e de ações que "pretendem imprimir um novo significado à experiência da escolarização". Como parte de tais discursos, existe o pressuposto de que as questões a serem resolvidas pelas crianças devem ser encaminhadas com a mesma naturalidade com que são resolvidos os problemas do cotidiano (BIN, 2012).

Para tanto, como diz Walkerdine (1998, p. 170), as professoras acreditam que "as crianças devem estar livres da intervenção adulta, isto é, em seu estado natural, como seres individuais não contaminados pela cultura". Isso significa que os problemas a serem resolvidos pelas crianças no desenvolvimento dos projetos devem surgir antes dos conceitos a serem construídos, no intuito de que o exercício do pensamento infantil se torne um ato funcional. Em suma, como aponta Leite (2007), o trabalho com projetos costuma ser apresentado como uma proposta inovadora, capaz de possibilitar a interdisciplinaridade e de promover a participação efetiva das crianças no contexto escolar.

Desse modo, não é de se estranhar que o trabalho com projetos decorrentes dos interesses das crianças seja apresentado nos relatórios de estágio como um imperativo para o exercício de uma docência considerada inovadora. A partir da descrição das propostas desenvolvidas em sala de aula, as acadêmicas enunciam que o trabalho com projetos possibilita que as crianças tenham liberdade para desenvolver a autonomia, a vivência de valores democráticos, o aprendizado pela experiência e o protagonismo. Associado a isso, também se observa uma descentralização do papel docente no processo educativo. Isso porque as acadêmicas entendem que o trabalho com projetos, por ser menos diretivo, possibilita que as crianças protagonizem a construção de seus conhecimentos. Por outro lado, corroborando as análises, Coutinho e Sommer (2011, p. 87) afirmam que, mesmo em uma educação ativa (como a pedagogia de projetos), na qual se vislumbra uma 
INTERESSE DAS CRIANÇAS | Rodrigo Saballa de Carvalho e Bianca Salazar Guizzo

docência progressista e menos diretiva em que supostamente se governa menos pelo fato de as crianças terem mais liberdade, "é lá que se governa mais, é lá que as relações de poder são potencializadas". O que ocorre é que o governamento sobre os objetos de conhecimento cede espaço para o governamento sobre a criança. Desse modo, apesar do valor central concedido à liberdade infantil o autocontrole das crianças é imprescindível para a operacionalização das propostas. Isso porque, segundo Popkewitz (1998), não há propostas pedagógicas isentas de relações de poder, por mais progressistas que possam parecer.

Outro aspecto reiteradamente destacado pelas acadêmicas é o fato de que o trabalho com projetos poderá romper com o ensino tradicional e, de modo correlato, transformar a realidade educacional. Diante dessa lógica de pensamento, as acadêmicas classificam as práticas desenvolvidas pelas professoras titulares das turmas como sendo tradicionais, ou seja, estagnadas, estéreis, segmentadas em áreas do conhecimento e baseadas no ensino de conteúdos. A esse respeito, Dubet (2006) afirma que o conceito de tradicional geralmente utilizado nos discursos pedagógicos denota a ideia de uma proposta de trabalho ultrapassada que deve ser criticada e superada. Por outro lado, conforme o referido autor, o conceito de inovador é utilizado para autenticar a qualidade de práticas consideradas progressistas, por não possuírem aulas convencionais e serem adeptas a um ensino ativo em que as crianças são consideradas protagonistas. No caso dos relatórios de estágio, o trabalho com projetos é apresentado como uma proposta inovadora, capaz de mudar os rumos da educação. Partindo desses apontamentos, pode-se dizer que as acadêmicas escrevem a partir de uma matriz pedagógica imersa em regras de formações discursivas historicamente constituídas. Ao escreverem sobre a importância do trabalho com projetos, as acadêmicas assumem uma posição na ordem do discurso pedagógico, no intuito de (se reconhecerem e) serem reconhecidas como docentes inovadoras que superaram o modo tradicional de atuar.

Em tal ordem do discurso, segundo Poças (2010), o trabalho com projetos remete diretamente ao que pode ser entendido como ensino ativo, centrado nos interesses e nas experiências das crianças. Conforme Bin (2012), o ensino ativo desenvolve os raciocínios dos indivíduos por meio da proposição de atividades que lidam com a aprendizagem de conhecimentos entendidos como úteis e práticos. No caso dos relatórios de estágio, o ensino ativo encontra-se diretamente associado à pedagogia de projetos, cuja visão pragmática de conhecimento tem como foco central a relação entre as atividades escolares e a vida, perspectiva na qual o conhecimento é construído pelas crianças.

Ao contrário do que as acadêmicas enunciam nos relatórios, a pedagogia de projetos, assim como a sondagem dos interesses das crianças, não é uma prática recente. Embora a organização do currículo por projetos de trabalho seja contemporaneamente reconhecida em nosso país em decorrência da tradução, publicação e ampla difusão dos livros de Hernández (1998) e Hernandéz e Ventura (1998), foi Kilpatrick (1918), inspirado nas proposições de Dewey (2011) sobre educação como experiência, quem teorizou inicialmente a respeito dessa proposta de trabalho.

Partindo do argumento de que a infância seria uma etapa da vida com valor em si mesma, Dewey (2011) ressaltou a importância desempenhada pela experiência no processo de aprendizagem. Por esse motivo, concebeu o ato pedagógico como uma problematização da experiência acompanhada pela reflexão a respeito de temas e de problemas que, desencadeados por uma experiência, desafiariam ativamente a criança no ato de conhecer. Nessa perspectiva, Dewey (2002) redimensionou o papel da criança no processo de aprendizagem e criou uma nova concepção de aluno. Isso porque o foco de sua proposta consistiu em lançar mão das motivações e dos interesses das crianças para a descoberta, pela experiência pessoal, de informações úteis a serem assimiladas.

A visão de Dewey (2011) de uma educação como experiência, na qual o aprendizado seria decorrente de uma conexão orgânica entre aspectos ativos e cognitivos, despertou a atenção de Kilpatrick que, em 1918, publicou um ensaio sobre projetos, no qual apresentou uma proposição 
metodológica a partir das ideias de seu inspirador. Nesse ensaio, ele apresentou o trabalho com projetos como um modo de se contrapor ao ensino tradicional da época e defendeu a possibilidade de reforma da sociedade a partir de transformações implementadas por meio da operacionalização da metodologia de projetos (LEITE, 2007).

Para tanto, Kilpatrick (1918) propôs que o trabalho com projetos deveria partir de uma situação-problema, em que a criança pudesse ser protagonista de seu processo de aprendizagem. Nesse contexto, definiu que os projetos poderiam ser de quatro tipos: 1) para incorporar uma ideia; 2) para desfrutar uma experiência estética; 3) para resolver um problema intelectual; 4) para obter um conhecimento. Defendia, assim, o trabalho com projetos como uma experiência propositiva, cuja função seria a condução do processo de aprendizagem a partir da mobilização do aprendiz. Nessa perspectiva, a escola passou a ser entendida como um laboratório onde as crianças deveriam descobrir por si próprias conhecimentos e habilidades necessários para apreenderem o mundo.

Bin (2012) refere que, a partir dessa perspectiva, a formação da infância passou a ter como foco o estabelecimento de uma relação permanente entre educação e vida. Em razão disso, o objetivo do trabalho pedagógico deixa de ser a preocupação do professor com uma visão propedêutica de ensino e passa a ser com a proposição de projetos relacionados aos interesses das crianças e à resolução de problemas no tempo presente. A partir do panorama apresentado sobre a emergência do trabalho com projetos, é possível dizer que essa pedagogia é apresentada como uma proposta progressista pelo fato de ter como foco a experiência das crianças e de ser organizada em torno de um problema a ser resolvido em sala de aula (HERNÁNDEZ, 1998 e HERNÁNDEZ; VENTURA, 1998). Os discursos sobre a importância da pedagogia de projetos vêm historicamente funcionando desde a sua emergência, por meio dos postulados escolanovistas, na produção de um regime de verdade que certifica a validade de tal proposta em oposição ao ensino tradicional, naturalizando-a e fazendo-a parecer inovadora e progressista. A partir de Palamidessi (1996), pode-se inferir que na produção desse regime de verdade prescreve-se certo modo de trabalho com as crianças, operam-se com tecnologias de poder e de saber cujo propósito é o governamento das subjetividades docentes.

\section{O “aprender a aprender" como meta da ação pedagógica}

Observei que na minha turma as crianças aprendiam sozinhas. A partir da ampla gama de situações propostas por meio do projeto desenvolvido, as crianças de forma autônoma buscavam respostas para os questionamentos que faziam parte do nosso roteiro de pesquisa. Obviamente que a aprendizagem das crianças foi muito mais significativa do que se eu, enquanto professora, tivesse transmitido informações. (Transcrição de Relatório de Estágio - A02)

O meu principal aprendizado durante a realização do estágio na Educação Infantil, foi a de que as experiências vivenciadas pelas crianças através dos projetos são muito mais importantes do que a mera transmissão de conhecimentos pela professora enquanto detentora do saber. Observei que as crianças aprendem por si mesmas e desenvolvem autonomia. Também percebi que escola e vida devem andar de mãos dadas para que as aprendizagens das crianças realmente sejam significativas. (Transcrição de Relatório de Estágio - A40)

As crianças de minha turma aprenderam a pesquisar. Através das propostas desenvolvidas no decorrer do projeto, elas conseguiram aprender sozinhas as etapas de uma pesquisa. Apenas possibilitei a vivência da pesquisa, pois foram elas que conduziram o processo. Tenho certeza que a professora titular da turma ficará surpresa com a autonomia das crianças. (Transcrição de Relatório de Estágio - A10) 
Fiquei empolgada com a realização do meu estágio na Educação Infantil. Foi um desafio conciliar educação
e vida no desenvolvimento das propostas. As crianças estiveram o tempo inteiro motivadas em relação ao
trabalho desenvolvido no contexto do projeto, pois tinham interesse em saber mais informações a respeito da
preservação da natureza. Desse modo, consegui perceber o desenvolvimento da autonomia das crianças que
fizeram parte de minha turma de estágio e a capacidade das mesmas de aprenderem sozinhas. (Transcrição
de Relatório de Estágio - A08)

Foucault (2005, p. 35) afirma que é sempre possível dizer o verdadeiro no espaço de uma exterioridade selvagem, mas que "nunca nos encontramos no verdadeiro se não obedecermos às regras de uma 'polícia discursiva' que deve ser reativada em cada um de nossos discursos". Em tal perspectiva, a partir da análise dos relatórios de estágio, foi possível perceber a recorrência de uma perspectiva educacional metacognitiva, a qual se assenta na perspectiva de que as crianças devem "aprender a aprender" (DUARTE, 2004; ARCE, 2004). Articulada com o relativismo cultural e epistemológico, essa corrente educacional apresenta práticas supostamente superadoras das formas de educação escolar consideradas tradicionais (POÇAS, 2010). O argumento central é que a escola, para formar para a vida, não deve ter um aspecto intelectualista e que aprender sozinho se situa em um nível mais elevado do que aprender em decorrência da transmissão de conhecimentos por alguém.

A perspectiva educacional metacognitiva, apresenta os seguintes posicionamentos: 1) as crianças devem aprender por si mesmas (ARCE, 2004); 2) o método de aquisição de conhecimentos é valorizado; 3) a atividade da criança deve partir dos seus interesses e necessidades (STEMMER, 2006); 4) a educação deve preparar as crianças para acompanhar as mudanças da sociedade do conhecimento (DUARTE, 2004). Como pode ser percebido, reivindica-se a centralidade da criança no processo educativo (DUBET, 2006). Nesse contexto, conforme aponta Stemmer (2006, p. 165), a criança é entendida como alguém que está em "via de tornar-se, por caminhos próprios, o que deve ser, construindo seu próprio conhecimento a partir de seus interesses e necessidades naturais".

Entende-se, então, que educar é diferente de instruir ou de ensinar e que a escola deve se tornar um espaço de "preparação da vida, pela vida, para a vida" (LUZURIAGA, 1967, p. 41). Desse modo, o professor é entendido como um facilitador, ou seja, como um coadjuvante do processo de aprendizagem, como fica claro nos relatórios. Nessa lógica, a intervenção docente é reduzida ao mínimo e a aprendizagem passa a ser entendida como vinculada a processos espontâneos pautados nos interesses das crianças. Corroborando o argumento, Prado e Azevedo (2012, p. 39) afirmam que se pode dizer então que "essa renovação conceitual visa enfatizar uma concepção de educação em que a proposição curricular é centralizada nos interesses da criança, considerada como protagonista do processo".

Sendo assim, conforme Dubet (2006), os conteúdos perdem progressivamente o seu valor, pois, na perspectiva metacognitiva, já não importa tanto incidir sobre as potencialidades intelectuais das crianças, sobre a cultura humana pregressa ou mesmo sobre a produção de novos conhecimentos. O foco é a criança e seus processos de aprendizagem. Para Arce (2004), essa noção de respeito ao universo infantil só vem confirmar que os processos espontâneos de aprendizagem infantil são o que há de mais importante na sala de aula.

O regime de verdade que tem o "aprender a aprender" como lema tem encontrado grande aceitação no contexto da formação de professores de Educação Infantil. Conforme Arce (2004), Poças (2010) e Prado e Azevedo (2012), tal consenso docente tem dificultado a elaboração de outras proposições pedagógicas que sigam uma direção diferente daquelas focalizadas exclusivamente no atendimento dos interesses das crianças, do seu cotidiano próximo e do "aprender a aprender" por meio da pedagogia de projetos. É nessa perspectiva, como pôde ser observado nos 
INTERESSE DAS CRIANÇAS | Rodrigo Saballa de Carvalho e Bianca Salazar Guizzo

excertos dos relatórios apresentados, que a pedagogia de projetos tem se afirmado como uma das mais progressistas e libertárias práticas pedagógicas contemporâneas.

\section{3| CONSIDERAÇÕES FINAIS}

Foucault (1995, p. 14) afirma que a verdade está circularmente "ligada a sistemas de poder, que a produzem e apoiam, e a efeitos de poder que ela induz e que a reproduzem". Desse modo, é possível inferir que os enunciados que constituem os discursos sobre docência veiculados nos relatórios de estágio não são provenientes da vontade, da liberdade e da autonomia das acadêmicas. O modo como elas descrevem a docência na Educação Infantil é efeito dos discursos pedagógicos em que estão inscritas, e não o contrário.

Conforme refere Popkewitz (1994), na dinâmica em que colocam em ação, os discursos sobre a docência atuam como um sistema de razão constituído por padrões de pensamento e ação que incorporam concepções particulares sobre a educação. A partir dessa lógica de pensamento, a análise de como os saberes sobre a docência na Educação Infantil vêm se constituindo historicamente possibilitou a problematização de regimes de verdade emergentes de uma matriz pedagógica cujas ressonâncias são decorrentes de postulados escolanovistas.

Como foi evidenciado no decorrer do artigo, os discursos sobre a docência presentes nos relatórios operam na produção de sujeitos governáveis através da utilização de estratégias que têm por finalidade administrar, controlar e normalizar a conduta das futuras docentes. Estas, ao definirem os interesses das crianças como princípio para o planejamento, a metodologia de projetos como meio e a metacognição (o "aprender a aprender") como fim da ação pedagógica na Educação Infantil, compartilham modos de pensar a educação das crianças. É através desses discursos que significados sobre a docência são constituídos, subjetividades são produzidas e novos sistemas éticos são introduzidos (POPKEWITZ, 1998; POÇAS, 2010).

Por outro lado, se for assumida a perspectiva de que os discursos sobre a docência presentes nos relatórios são produzidos a partir de relações de poder e do tipo de lógica histórica que os movimenta, é possível problematizá-los e desnaturalizá-los, retirando-os de uma dimensão de inevitabilidade. Como bem lembra Foucault (1995), não se trata de libertar a verdade de todo o sistema de poder, mas de desvincular o poder da verdade das formas de hegemonia (sociais, econômicas, culturais) no interior das quais ela opera. Talvez dessa forma, seguindo as trilhas propostas pelo filósofo, seja possível que as acadêmicas problematizem os discursos pedagógicos que as incluem (e as levam a se incluírem) em sistemas de pensamento que as tornam cada vez mais governáveis, percebendo a constituição histórica do produtivo regime de verdade que faz com que se identifiquem com um único modo de exercício da docência, tornando-se todas professoras de determinado tipo. 


\section{Referências}

ARCE, Alessandra. Pedagogia da Infância ou fetichismo da infância? In: DUARTE, Newton (Org.). Crítica ao fetichismo da individualidade. Campinas: Autores Associados, 2004. p. 146-168.

BIN, Ana Clara. Concepções de conhecimento e currículo em W. Kilpatrick e implicações do método de projetos. 2012. 120 f. Dissertação (Mestrado em Educação) Programa de Pós-Graduação em Educação, Faculdade de Educação, Universidade de São Paulo, São Paulo, 2012.

CLAPARÈDE, Edouard. A Educação Funcional. São Paulo: Companhia Editora Nacional, 1940.

COUTINHO, Karyne Dias; SOMMER, Luis Henrique. Discursos sobre a formação de professores e artes de governar. Currículo sem Fronteiras, São Paulo. v. 11, p. 86-103, jan./jun. 2011.

DEAN, Mitchell. Governmentality: power and rule in modern society. London: Sage, 1999.

DECROLY, Ovide. Función de globalización y enseñanza. Barcelona, Espanha: Biblioteca Nueva, 2007.

DEWEY, John. A Escola e a Sociedade. Portugal: Relógio D’Água Editores, 2002. zes, 2011.

Experiência e educação. Petrópolis, RJ: Vo-

DUARTE, Newton (Org.). Crítica ao fetichismo da individualidade. Campinas, SP: Autores Associados, 2004.

DUBET, François. El declive de la institución: profesiones, sujetos e individuos ante la reforma del Estado. Barcelona: Gedisa Editorial, 2006.

FABRIS, Eli Terezinha Henn; SILVA, Roberto Rafael Dias da. Análise de uma matriz pedagógica escolar: a invenção da docência e de pessoas em uma escola de periferia. Currículo sem Fronteiras, Porto Alegre, v.15, n.2, maio/agosto, 2015. p. 492-507.

FOUCAULT, Michel. Microfísica do poder. Rio de Janeiro: Graal, 1995.

A ordem do discurso. São Paulo: Loyola, 2005.

A arqueologia do saber. Rio de Janeiro: Forense Universitária, 2007.

Nascimento da biopolítica. São Paulo: Martins Fontes, 2008a.

Segurança, território e população. São Paulo: Martins Fontes, 2008b.
GORE, Jennifer M. Foucault e educação: fascinantes desafios. In: SILVA, Tomaz Tadeu (Org.). O sujeito da educação: estudos foucaultianos. Petrópolis, RJ: Vozes, 1994. p. 9-20.

HERBART, Friedrich. Pedagogia Geral. Lisboa: Fundação Calouste Gulberkian, Gráfica de Coimbra, 2003.

HERNÁNDEZ, Fernando. Transgressão e mudança na educação: os projetos de trabalho. São Paulo: Artmed, 1998.

HERNÁNDEZ, Fernando; VENTURA, Montsserrat. A organização do currículo por projetos de trabalho: o conhecimento é um caleidoscópio. São Paulo: Artmed, 1998.

KILPATRICK, William H. The Project Method: The Use of the Purposeful Act in the Educative Process. Teachers College Record, New York, v. 19, n. 4. p. 319-335, 1918.

LEITE, Ana Cláudia Caldas de Arruda. A noção de projeto na educação: o "método de projeto" de William Heard Kilpatrick. 2007. 72 f. Dissertação (Mestrado em Educação) - Programa de Pós-Graduação em Educação, Pontifícia Universidade Católica de São Paulo, São Paulo, 2007.

LUZURIAGA, Lorenzo. La educación nueva. Buenos Aires: Editorial Lozada, 1967.

MATTOS, Sérgio Túlio Generoso. A noção de interesse na Escola Nova: formulações teóricas e a interpretação de Anísio Teixeira de 1924-1932. 2008. 107 f. Dissertação (Mestrado em Educação) - Programa de Pós-Graduação em Educação, Faculdade de Educação, Universidade Federal de Minas Gerais, Belo Horizonte, 2008.

PALAMIDESSI, Mariano Ismael. La producción del "maestro constructivista" en el discurso curricular. Educação \& Realidade, Porto Alegre, n. 21, p. 191-213, jul./ dez. 1996.

POÇAS, Jaqueline de Menezes Rosa. Projetos de trabalho e formação docente: novos sujeitos, novas práticas de governamento. 2010. 118 f. Dissertação (Mestrado em Educação) - Programa de Pós-Graduação em Educação, Universidade Luterana do Brasil, Canoas, 2010.

POPKEWITZ, Thomas S. História do Currículo, Regulação Social e Poder. In: SILVA, Tomaz Tadeu da (Org.). O sujeito da Educação: Estudos foucaultianos. Petrópolis: Vozes, 1994. p. 173-210. 
INTERESSE DAS CRIANÇAS | Rodrigo Saballa de Carvalho e Bianca Salazar Guizzo

PRADO, Alessandra Elisabeth Ferreira Gonçalves; AZEVEDO, Heloisa Helena Oliveira. Currículo para a Educação Infantil: argumentos acadêmicos e propostas de "educação" para crianças de 0 a 5 anos. In: ARCE, Alessandra; JACOMELI, Mara Regina Martins (Org.). Educação Infantil versus Educação Escolar? Entre a (des)escolarização e a precarização do trabalho pedagógico nas salas de aula. Campinas: Autores Associados, 2012. p. 33-52.

SOMMER, Luis Henrique; COUTINHO, Karyne Dias. Formação docente para um currículo inclusivo: armadilhas da linguagem. In: BONIN, lara Tatiana; RIPOLL, Daniela; KIRCHOF, Edgar Roberto; POOLI, João Paulo (Org.). Cultura, identidade e formação de professores: perspectivas para escola contemporânea. Canoas: ULBRA, 2008. p. 17-32.

STEMMER, Márcia Regina Goulart da Silva. Educação Infantil e pós-modernismo: a abordagem de Reggio Emilia. 2006. 182 f. Tese (Doutorado em Educação) Programa de Pós-Graduação em Educação, Universidade Federal de Santa Catarina, Florianópolis, 2006.
TEIXEIRA, Anísio Spínola. Pequena introdução à filosofia da educação: a escola progressiva ou a transformação da escola. São Paulo: Editora Nacional, 1967.

VEIGA-NETO, Alfredo. Educação e governamentalidade neoliberal: novos dispositivos, novas subjetividades. In: BRANCO, Guilherme Castelo; PORTOCARRERO, Vera (Org.). Retratos de Foucault. Rio de Janeiro: Nau, 2000. p.179-217.

WALKERDINE, Valerie. Uma análise foucaultiana da pedagogia construtivista. In: SILVA, Tomaz Tadeu da (Org.). Liberdades reguladas: a pedagogia construtivista e outras formas de governo do eu. Petrópolis, RJ: Vozes, 1998. p. 143-216. 